The four patients were men with an average age of 50 years and all had a history of long-standing back pain. One patient had taken 600 tablets of codeine compound as well as 600 of paracetamol in the two months before he was admitted to hospital and had consumed analgesics in a lower dosage over the previous eight years.

Another admitted taking large doses of salicylate, phenacetin, and paracetamol for at least nine months. A third had been in the habit of taking codeine compound tablets for many years, and though he denied taking these in "large" doses, he had been admitted at one time with constipation induced by codeine. The fourth patient had been taking Codis and paracetamol for radiologically proved degenerative lumbar spine disease.

\section{Discussion}

Study of the necropsy records of the London Hospital raised the suspicion that a new disease appeared in the East End of London early in the 1950 s. Before that time retroperitoneal fibrosis, or anything resembling it, is entirely absent from the necropsy records, which have been kept since 1907. It is true that once a new disease has been described it becomes more easy to recognize it, and cases might have gone undetected before Ormond's first case report in 1948. ${ }^{1}$ Nevertheless, it may not be entirely coincidental that the first reports of analgesic nephropathy and retroperitoneal fibrosis appeared at about the same time. ${ }^{18}$ Our review of the histories of patients known to have had retroperitoneal fibrosis supports such an association.

The impression has grown that non-malignant retroperitoneal fibrosis may not be a single disease entity but rather the end result of various pathological processes which may affect different parts of the ureter or retroperitoneal connective tissue. Most reports refer to a hard white plaque of fibrous tissue encasing the aorta and vena cava and their larger branches and drawing the ureters together towards the midline. This perivascular distribution of the fibrous tissue made Mitchison ${ }^{9}$ in his study of 40 cases suggest that damage to the aortic wall might be the essential aetiological factor both in cases without other obvious cause and in those related to methysergide consumption.

When other factors are found to be associated the distribution of the fibrous tissue seems to be different. Thus in the cases related to urinary tract infection described by Vest and Barelare ${ }^{10}$ and Behrens and Holland ${ }^{11}$ the retroperitoneal fibrosis did not follow the usual pattern. It was principally periureteric and Behrens and Holland gave it the name "periureteritis plastica" to distinguish it from the classical retroperitoneal plaque.

Phills et al. ${ }^{12}$ described three siblings with the sickle-cell trait who developed retroperitoneal fibrosis and renal papillary necrosis. In one of these the fibrosis was a "periureteral hose-like sheath"- a description which would have fitted both our cases and those described by MacGregor et al. ${ }^{5}$ exactly. Since the sickle-cell trait and analgesic abuse may each be associated with lesions of the renal papilla and the ureter there may be similar pathogenetic factors involved, though the exact mechanisms remain unknown.

Discussions still continue over the relative importance of the various drugs which might be incriminated in analgesic nephropathy (British Medical fournal, 1974). All our patients had consumed phenacetin (in case 2 the patient consumed Codis at a time when phenacetin was a constituent), as had those described by MacGregor et al. ${ }^{5}$ Possibly, however, the damage is due to the combined effects of several drugs.

We suggest that one form of retroperitoneal fibrosis may result from the action of various analgesic drugs. Two recommendations follow: firstly, a very careful drug history should be taken from every patient who may have retroperitoneal fibrosis or any other unusual obstruction to the ureter. Secondly, attention should be paid to the histological changes in the kidneys of patients with retroperitoneal fibrosis, since the renal damage may in part be due to a coexisting and unsuspected analgesic nephropathy as well as obstruction.

\section{References}

1 Ormond, J. K., Fournal of Urology, 1948, 59, 1072.

2 Wangenknecht, L. V., and Auvert, J., Urologia Internationalis, 1971, 26, 185 .

3 Webb, A. J., and Dawson-Edwards, P., British fournal of Surgery, 1967,

54, 508.
${ }^{4}$ Packham, D. A., and Yates-Bell, J. G., British fournal of Urology, 1968, 40, 207.

40, 207.

6 Tresidder, G. C., Blandy, J. P., and Singh, M., Urologia Internationalis,

1971, 27, 144.
Tresidder, G. C., British fournal of Urology, 1957, 29, 130.

8 Spuhler, O., and Zollinger, H. U., Zeitzschrift für klinische Medizin, 1953, 151,1 .

${ }^{9}$ Mitchinson, M. J., fournal of Clinical Pathology, 1970, 23, 681.

10 Vest, S. A., and Barelare, B., Fournal of Urology, 1953, 70, 38

11 Behrens, M. M., and Holland, J. M., fournal of Urology, 1967, 97, 829.

12 Phills, J. A., et al., Canadian Medical Association fournal, 1973, 108, 1025

\title{
The Medical Student as Behavioural Psychotherapist
}

\section{R. S. STERN}

British Medical fournal, 1975, 2, 78-81

\section{Summary}

A group of medical students were randomly selected from a larger group to carry out behaviour therapy under \footnotetext{
Academic Department of Psychiatry, St. Bartholomew's Hospital,
London, EC1

R. S. STERN, M.D., M.R.C.PSYCH., Lecturer in Psychiatry
}

supervision. Ten patients with phobic disorders and two with obsessive-compulsive neurosis were treated, and the results, assessed by ratings of proved reliability, compared favourably with other studies in which psychiatrists or nurses acted as therapists. A questionnaire survey showed that students involved in therapy had a more favourable opinion about this kind of treatment than those receiving only theoretical instruction. The results suggested not only that medical students make good behavioural psychotherapists but also that the subject is a worthwhile training experience which warrants inclusion in the curriculum. 
This paper reports the results of treatment by medical students of a series of patients suffering from various phobic and obsessive-compulsive disorders. The study was performed to provide an opportunity for a group of medical students to carry out behaviour therapy under supervision. Agras ${ }^{1}$ suggested that behavioural techniques may be useful for demonstrating to medical students the relevance of the experimental behavioural sciences to clinical medicine. From a questionnaire study there appeared to be a need for this kind of teaching. ${ }^{2}$ Marks et al. ${ }^{3}$ showed that psychiatric nurses could obtain results at least as good as psychiatrists and psychologists using similar psychological treatment in comparable psychiatric populations. It remained to be shown that medical students could achieve comparable results. In addition the study provided an opportunity for assessing students' attitudes to behavioural treatments and whether these attitudes were modified by experience of treating patients. The students themselves had expressed the wish to take part in the treatment of patients. This gave impetus to the present study despite the view that "many undergraduate teachers will argue that practical treatment techniques are not appropriate in the medical school phase, but should be taught later in the pre-registration period when the student has graduated."4

\section{Method}

Fifteen students were randomly selected from a total of 72 and given eight supervision sessions at weekly intervals. All patients were outpatients and were first assessed diagnostically by a psychiatrist and selected if suitable. Two students were responsible for each patient, and they documented each stage in the treatment. Early in their training the treatment sessions were carried out jointly with the psychiatrist, but as competence was acquired the joint sessions were reduced until the students were carrying out treatment by themselves.

The most commonly used technique was exposure (flooding) in vivo. Four patients with agoraphobia, six with other phobic disorders, and two with obsessive-compulsive neurosis were treated. The main target symptoms were rated by the supervising psychiatrist and by the patient before and after each treatment session, and at follow-up using ratings of proved reliability ${ }^{3}$.

Before each treatment session a group of eight students would discuss the treatment with the psychiatrist in a seminar setting, and the aims of the session would be delineated. After the seminar the group would meet again to report the results to the group and discuss these. Each student kept a written record of the details of each treatment session, noting the patients' reactions and his own feelings at each stage during therapy.

\section{Results}

The results of student-therapist treatment of phobic disorders are shown in the fig. Each phobic patient received between three and seven sessions. A rating of 7 indicates almost complete avoidance of the phobic situation and a rating of 2 shows uneasiness but no avoidance, so that the changes in ratings after treatment show significant improvement. The patients with obsessive-compulsive neuroses were not rated systematically, and so these results are excluded from fig. 1. However, good clinical results were obtained in these patients.

The results can be compared with those obtained by the newly conceived nurse-therapists, who treated a mixture of 9 agoraphobics, 10 specific phobics, and 4 social phobics. ${ }^{3}$ The present study showed an almost identical overall satisfactory outcome as Marks et al. obtained, ${ }^{3}$ and, as those authors pointed out, their results were as good as those obtained by psychiatrists using flooding in vivo for phobic disorders. ${ }^{5}$.

To assess the attitudes of medical students to behaviour therapy the whole group of 72 students were given a question-

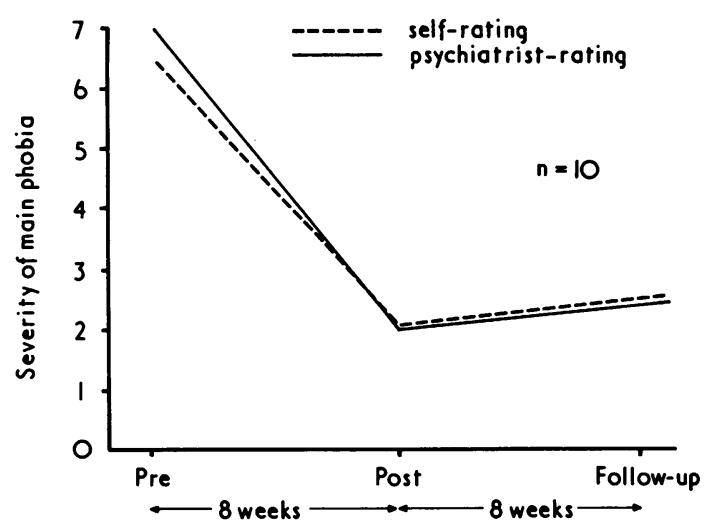

Improvement in main phobia after treatment

naire modified from that of Brady. ${ }^{2}$ The results for the 15 students who received experience in behavioural techniques (group B) are set out separately from the other students (group A) in tables I, II, and III. It can be seen that $60 \%$ of group A thought behaviour therapy should be a required course in the medical school curriculum, and $66 \%$ of group B thought it should be an elective course. No student in either group thought course material in the subject should be absent. In group A 3\% thought behaviour therapy was a fad which will pass, leaving at most a small impression on British psychiatry, but none of group B thought this. The majority of both groups thought behaviour therapy was a distinctive approach which will

TABLE I-Students' Opinion of Place of Behaviour Therapy in Medical School Curriculum

\begin{tabular}{l|c|c|c|c}
\hline & \multicolumn{2}{|c|}{ Group A } & \multicolumn{2}{c}{ Group B } \\
\cline { 2 - 5 } & No. & $\%$ & No. & $\%$ \\
\hline A required course & 34 & 60 & 5 & 33 \\
\hline An elective course & 23 & 40 & 10 & 66 \\
\hline No course material & 0 & 0 & 0 & 0 \\
\hline
\end{tabular}

TABLE II-Students' Opinion of Future Role of Behaviour Therapy in British Psychiatry

\begin{tabular}{|c|c|c|c|c|}
\hline & \multicolumn{2}{|c|}{ Group A } & \multicolumn{2}{|c|}{ Group B } \\
\hline & No. & $\%$ & No. & $\%$ \\
\hline $\begin{array}{l}\text { Behaviour therapy is a fad which will pass } \\
\text { and leave at most a small lasting impression } \\
\text { on British psychiatry }\end{array}$ & 2 & 3 & 0 & 0 \\
\hline $\begin{array}{l}\text { Behaviour therapy as a distinctive approach will } \\
\text { gradually become part of the mainstream of } \\
\text { British psychiatry, where it will exert a lasting but } \\
\text { moderate influence }\end{array}$ & 49 & 87 & 9 & 60 \\
\hline $\begin{array}{l}\text { Behaviour therapy as a distinctive approach will } \\
\text { become one of the major directions in which } \\
\text { British psychiatry will move }\end{array}$ & 6 & 10 & 5 & 33 \\
\hline $\begin{array}{l}\text { In time behaviour therapy will become the } \\
\text { predominate direction in which British psychiatry } \\
\text { will move }\end{array}$ & 0 & 0 & 1 & 7 \\
\hline
\end{tabular}

TABLE III-Students' Opinion about Efficacy of Behaviour Therapy for Phobic and Obsessional Disorders

\begin{tabular}{l|c|c|c|c}
\hline & \multicolumn{2}{|c|}{ Group A } & \multicolumn{2}{c}{ Group B } \\
\cline { 2 - 5 } & No. & $\%$ & No. & $\%$ \\
\hline No help at all & 0 & 0 & 0 & 0 \\
\hline Slightly helpful & 2 & 4 & 1 & 7 \\
\hline Moderately therapeutic & 33 & 58 & 5 & 33 \\
\hline Definitely therapeutic & 22 & 38 & 9 & 60 \\
\hline
\end{tabular}


gradually become part of the main stream of British psychiatry. More of group B $(33 \%)$ than group A $(10 \%)$ thought that behaviour therapy was a distinctive approach that will become one of the major directions in which British psychiatry will move.

Finally the two groups were asked whether behaviour therapy can help phobic and obsessional patients. Of group B $60 \%$ thought it could help a great deal and 33\% thought it could help moderately, whereas only $38 \%$ of group A thought it could help a great deal and $58 \%$ thought it could help moderately.

A representative sample of patients and their treatment are described below to illustrate the method.

\section{CASE 1}

A 38-year-old motor fitter with a history of fainting since the age of 16 years fainted at his own wedding at the age of 22 and later on began to feel faint whenever he felt "trapped in." This happened especially when he thought he was the centre of attraction, and because of this he avoided crowds, theatres, and trains and always sat near the exit when travelling by bus. He was investigated for an organic cause of the fainting attacks, and simple vaso-vagal faints were diagnosed. His symptoms limited his social life, and prevented promotion at work as there were situations he would not enter.

The patient had a happy childhood in the East End of London, and entered apprenticeship to be a motor mechanic as soon as he ended his National Service in the Army. He enjoyed his job and was happily married with three children.

Treatment consisted of three sessions of about 2 hours' duration each. Firstly, two medical students accompanied the patient to the hospital canteen where he was asked to remain even if he felt unwell. $\mathrm{He}$ was told by one student "even if you should faint you are in the best of hands as we will know exactly what to do to revive you". The patient told the students, "Only women faint, I've never known a man who faints like I do." He was reassured by one of the students, who was male, that he himself had fainted during his initial days while learning anatomy as a medical student. The student commented, "The patient seemed to gain considerable reassurance from this fact".

In the second session "modelling" procedures were employed in which the students demonstrated to the patient appropriate coping behaviours. They showed how it was possible to put his head between his knees to prevent faintness and showed that this action could be carried out even in a public place if the pretext of looking for something on the floor was employed. Later, one of the students stood on a table in the cafeteria to attract attention and having done so, encouraged the patient to do likewise. The patient flushed and refused to do this himself. The second student defended the patient's action saying laughingly, "No one in his right mind would want to stand on a table here." The patient subsequently recollected this experience as the key point in therapy: "After being so embarrassed when that student was standing on the table and everyone was looking at us I can never be embarrassed again."

He remained symptom-free at six-month follow-up.

\section{CASE 2}

This patient was an 18-year-old student teacher who had been afraid of dogs since early childhood. She had to cross the road if there was any possibility of encountering a dog and could not venture into public parks for fear of meeting a dog off the lead. The patient's parents recounted how she had been frightened at the age of 2 years when a large Alsatian dog jumped on her pram, but the patient herself had no conscious memory of this.

Treatment consisted of three sessions of 2 hours' duration each. Four medical students carried out flooding in vivo or "confrontation" therapy, in which the patient was encouraged to remain in contact with a small dog. At first the patient agreed to remain in the same room only if the dog was kept at least $12 \mathrm{ft}(3 \mathrm{~m})$ away. The medical students played with the dog, stroked and petted it, and by a combination of modelling and flooding the patient was gradually encouraged to stroke the dog. By the third session the patient allowed the dog off the lead and was stroking the dog's head without undue anxiety. A medical student commented, "The patient learnt to grit her teeth and faced the fear. Gradually the anxiety went away and she was ready for the next step, all the time becoming more and more involved in the feared situation."
After the first session another medical student reported, "The patient was voluntarily playing with the dog, stroking his belly, and saying she wanted to buy a dog. I found this very surprising and satisfactory to witness."

The patient was able to go about freely at six-month follow-up, could stroke dogs, and could visit public parks.

\section{CASE 3}

A 53-year-old housewife began to suffer from anxiety attacks on tube trains 10 years previously. Two years later she started to avoid cinemas and crowded places and then found it increasingly difficult to use the public transport to go shopping. She had completely avoided lifts for the same length of time and eventually found it impossible to leave home to shop for the family. Her father died of a coronary thrombosis five years previously, since when the patient became more disabled and developed a tight feeling and discomfort in the upper part of her chest, which it was thought might represent an identification with the symptoms manifested by her deceased father. The patient had received minor tranquillizers for many years from her general practitioner with little effect.

Treatment consisted of seven sessions of flooding in vivo carried out by two student-therapists. For the first session the supervisory pyschiatrist (R.S.) accompanied the student therapists in order to instruct them in the technique, but subsequent sessions were carried out by student-therapists alone. The patient was first taken to a large square in front of St. Paul's Cathedral, and then encouraged to venture into near-by shops while her therapists remained in the vicinity. It became clear that the patient developed ways of cutting herself off from the anxiety of the situation and not facing up to it. One of these was by talking continuously to relieve anxiety. This was pointed out to her and she was not allowed to do this on subsequent sessions. One of the students also pointed out, "She clearly focuses all her attention on the goods in the shop, hence fails to face up to the situation she is in and thereby reduces her anxiety". In the discussion that followed, the student-therapists agreed to point this out to the patient and prevent it. However, when it was thought beneficial for patients to express their anxiety so that it could be faced they were encouraged to do so: "We got her to verbalize her fear of the lift getting stuck and her 'going berzerk,' and of her memory of her friend's death in a lift four years ago."

After the fourth treatment one of the student-therapists spent a session explaining the aims of treatment to the patient's husband. The student wished to do this because in his own words: "Her husband appeared basically unconcerned about his wife's problem. He felt the real problem was one of his wife's shyness and inadequacy. He did not seem to understand the aims or methods of his wife's treatment. These were explained, and it was emphasized that he had to continue to supervise her activities at home to ensure that she did not slip back between sessions."

The last two sessions were spent in sending the patient on long unaccompanied journeys on public transport, where she met the therapists at prearranged points. At the completion of treatment the student-therapist commented: "The patient no longer takes tranquillizers and feels much better, she feels no uneasiness walking in streets and shops alone. She does still feel uneasy, but will travel on buses and tube trains alone. Her husband is informed and interested in the treatment and ensures she carries on with the aims of therapy at home."

\section{CASE 4}

A 56-year-old caretaker in a City office-block was suffering from an obsessional neurosis characterized by a compulsive urge to check and recheck light switches and door locks. His night-round lasted four hours instead of 30 minutes because he could not resist the impulse to return and check each door and switch several times.

The student-therapists treated him with a single session of response-prevention in which they accompanied him on his rounds and firmly dissuaded him from checking more than was strictly necessary. They achieved this by distracting him with conversation and encouraging him to proceed rapidly to the next task rather than return to an earlier one. The following night he was able to complete his rounds without excessive checking, and a student commented that the therapeutic effect must have been achieved when the therapists showed the patient that failure to carry out the ritual did 
not lead to disaster. At six-month follow-up the patient remained free of compulsive checking.

\section{CASE 5}

A 28-year-old clerk with a severe obsessional neurosis had been referred for assessment for leucotomy. He was troubled by many ruminations and rituals, but the most distressing symptom was his reluctance to be in the same room as his 9-month old baby. He had an irrational fear that the child might swallow a tablet which he might have overlooked in his pockets or trouser turn-ups. The students treated him in a single two-hour session by filling all his pockets with tablets and then persuading him to play with some children. He then went home and was able to have close contact with his child for the first time. There had been no recurrence of his symptom at ninemonth follow-up.

\section{Discussion}

It appears that medical students can carry out behavioural techniques under supervision in the treatment of phobic and obsessional disorders and obtain results which are at least as good as those obtained by nurse-therapists and psychiatrists. Though it could be argued that teaching specialized techniques to students most of whom may never employ the methods in their professional career is a waste of time, comments made by the students themselves imply the reverse. All 15 students who had experience of behaviour therapy said how much they enjoyed having direct therapeutic involvement with patients. They found it rewarding to witness improvement in the patients they treated and as in case 1 were able to play a large part in improvisation of the treatment. As a result of their treatment of the patients they obtained further details of the history which did not come to light before-for example, the traumatic experience concerning lifts experienced many years previously by patient No. 3 (a friend had been killed in a lift 24 years before).

Some of the remarks made by students in their written account of treatment sessions were elucidatory: "The situation was very similar to persuading a small child to dive into a pond-the longer one waits, the worse it becomes." The same student remarked about the above patient "this fear of lifts is obviously her most severe phobia, but it is important to ask if it is the most serious. I tend to think not. The patient lives in a small village and her most serious problem is public transport, which is far more handicapping than lifts, which would not be encountered so much." It was decided therefore to concentrate on the patient's difficulties on public transport, which were completely overcome after six sessions.

The questionnaire results underline the importance of behaviour therapy in the medical students' training in Great Britain already suggested by the results obtained by Brady in the U.S.A. ${ }^{2}$ The fact that most of group B (those who had experience of behaviour therapy) thought this experience should be on an elective rather than compulsory basis implies that this kind of approach can be taught only to those willing to learn and should not be forced upon them. However, the fact that all of the 15 students arbitrarily chosen enjoyed the experience speaks for itself. On the whole group B were more impressed by the role of behaviour therapy than group A, which might be expected to be the case as a result of their positive experience. When these students graduate in medicine, presumably they may well be more inclined to refer patients for such treatments than group A. Some of the enthusiasm from group B about behaviour therapy may have been communicated to their colleagues, and this would contribute to the latter's attitude, but there are still differences between the two groups confirming the effect of participation in therapy.

I wish to thank Dr. M. Lipsedge, who supervised the students treating the two obsessional patients. Both he and Professor Linford Rees provided encouragement and support during the study. The students who devoted their time so willingly to treatments also deserve thanks.

\section{References}

${ }^{1}$ Agras, W. S., fournal of Behaviour Therapy and Experimental Psychiatry, $1971,2,219$.

2 Brady, J. P., Fournal of Nervous and Mental Disease, 1973, 157, 21.

${ }^{3}$ Marks, I. M., Connolly, J., and Hallam, R. S., British Medical fournal, 1973, 2, 156.

4 Walton, H., British fournal of Psychiatry, 1968, 114, 1417.

${ }^{5}$ Boulougouris, J., Marks, I. M., and Marset, P., Behaviour Research and Therapy, 1971, 9, 7.

${ }^{6}$ Watson, J. P., Gaind, R., and Marks, I. M., British Medical fournal 1971, 13. 1,

\footnotetext{
Medical Department of Erlangen-Nuremberg University, Erlangen, West Germany

L. WITZEL, M.D., Senior Registrar
(Present address: Department of Medicine, University of Berne, CH-3008 Berne, Switzerland)
}

space 24 hours before death and $26 \%$ at 15 minutes before death.

A control group of patients with serious, but not fatal, illness were also studied. There was a contrast in attitude to death between the dying patients and the ill but not dying controls. The dying were resigned to their aproaching death, experienced little or no fear, and did not wish to know about their illness, whereas the control patients wanted information about their condition and feared death, though few thought they would actually die.

The relief of physical symptoms in the dying is important. There was often a brief improvement in condition, with reduced need for analgesic, shortly before death. 